\title{
KN3
}

\section{Shale Gas Project Development}

\section{Hartman* (Weatherford Laboratories)}

\section{SUMMARY}

Shale gas reservoirs pose unique challenges when undertaking field development. To put it simply, shale gas reservoirs are source rocks. These organic rich mudstones contain extreme vertical and lateral heterogeneity, are dominated by nanometer sized pores, have complex storage mechanisms, and require costly hydraulic fracture stimulation to produce economic quantities of gas. 


\section{Weatherford"}

LABORATORIES

\section{Unconventional Petroleum Reservoir Prospect Appraisal}

EAGE Shale Gas Workshop, September 21-24, 2014, Dubai, U.A.E.

Chad Hartman - Chief Technical Advisor WFT Labs Unconventional Reservoir Services

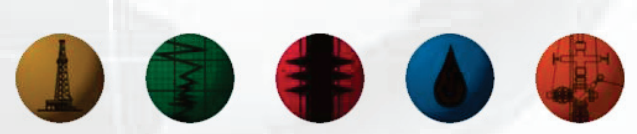

\begin{tabular}{ll} 
40 LABORATORY & NORTH AMERICA \\
LOCATIONS IN & Canada \\
22 COUited States \\
& $\begin{array}{l}\text { EUROPE } \\
\text { Norway } \\
\text { United Kingdom } \\
\text { Kazakhstan }\end{array}$ \\
\hline
\end{tabular}

For contact information, please visit our website: www.weatherfordlabs.com

\section{Disclaimer on Nomenclature}

The term "Shale" is used throughout this course and is in no way confined to the classic definition of the word. Throughout the development of, and eventual successful production from, unconventional sedimentary strata, U.S. operators have liberally used the word to represent any tight, fine grained, organic rich formation. These can be, or contain components, of siliceous, calcareous, clastic, biogenic, authigenic, or clay rich minerals. They can also contain varying degrees of organic matter and organic matter types and can be sequenced such that a given stratigraphic package includes thin or thick laminae of all of the above.

Shale: A fine grained, thinly laminated or fissile, detrital sedimentary rock form by the compaction and consolidation of clay, silt, or mud. The composition is characterized by an appreciable content of clay minerals, or derivatives from clay minerals, and a high content of detrital quartz. SPWLA Glossary of Terms and Expressions Used In Well Logging, Second Edition 1984 


\section{Essential Elements and Processes of a Petroleum System}

- Essential Elements:

- A petroleum source rock

- A petroleum reservoir rock

- A seal rock

- An overburden rock

- Essential Processes:

- Trap formation

- Generation - migration accumulation of petroleum

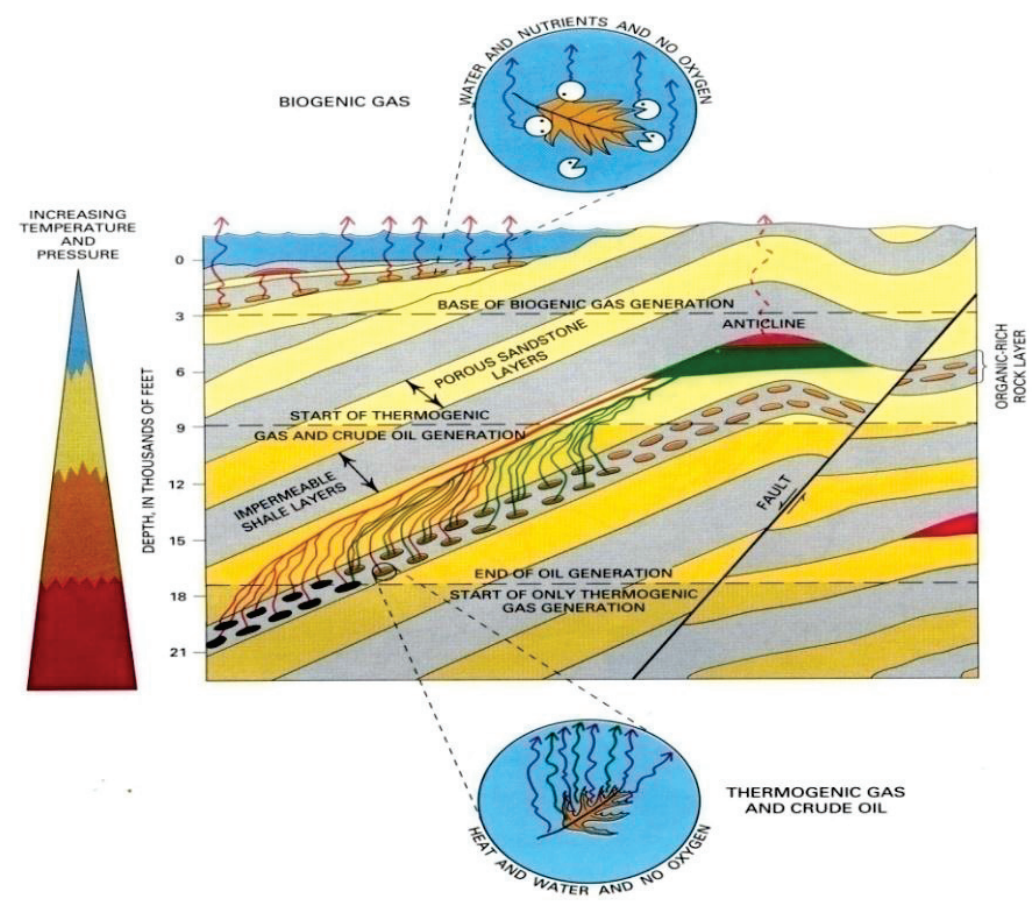

Weatherford

\section{Exploration Risk}

- Risk: The probability of spending exploration funds without economic success.

- Successful exploration depends upon:

- The existence of a trap

- The accumulation of sufficient petroleum charge

- Preservation of the entrapped petroleum

- Successful exploitation depends upon:

- Sufficient primary porosity permeability

- Adequate geomechanical properties to facilitate generation of large stimulated reservoir volumes and fracture conductivity

- Fit-to-purpose completion and stimulation design 


\section{Shale Gas-Oil Project Development: Sub-surface Complexity}

- Highly variable matrix density and presence of TOC complicate porosity estimates

- Non Archie rocks: Water resistivity and clay corrected Archie parameters are unknown

- Non Darcy transport mechanisms

- Complex storage mechanisms

- Extreme vertical and lateral reservoir heterogeneity

- Economic production requires aggressive, costly completion strategies

\section{Cumulative Effects of Unconventional Reservoir Complexity:}

- Highly productive wells are almost always limited to basin/field "fairways" with marginal to poor production in the larger, regionally massive areas of the basin.

- On average, recovery factors for shale gas plays range from 10-30\% of OGIP and shale oil plays range from $2-7 \%$ of OOIP. Furthermore initial production rates will typically decline by $70-80 \%$ within a year. As a result sustained continuous drilling of new wells (on the order of hundreds to thousands) are required annually to sustain target cumulative production volumes.

- A "blind" statistical drilling, completions, and production approach will only result in net loss of Cap-Ex.

Weathertord

\section{Eagle Ford Wet Gas Production Decline Curves at the Hawkville Field}

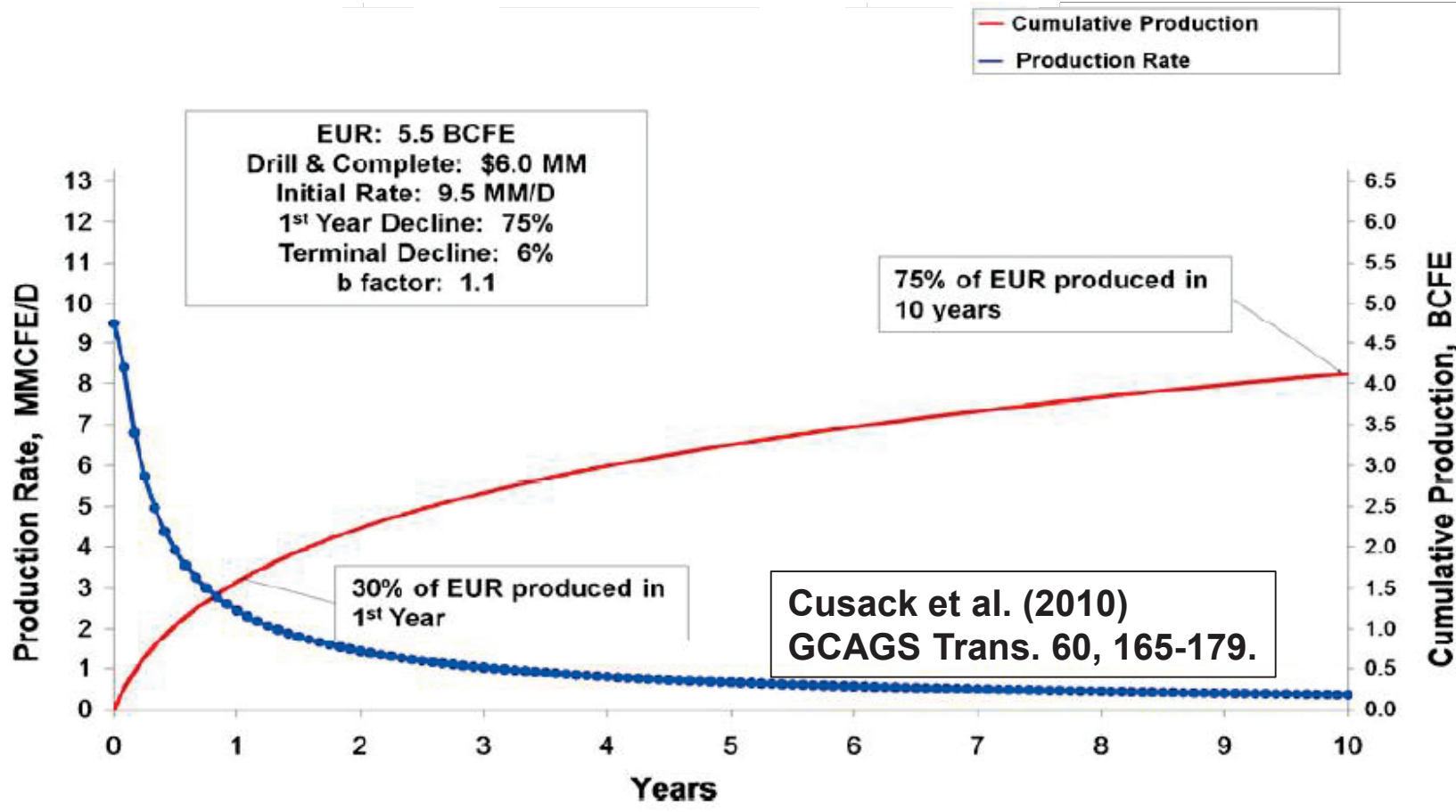

Figure 17. Type production decline curve of a Hawkville Field well showing that $75 \%$ of the $5.5 \mathrm{BCF}$ EUR (estimated ultimate recovery) (projected over a 30 year life) is recovered in the first 10 years. 


\section{Shale Gas-OII Field Development- Execution}
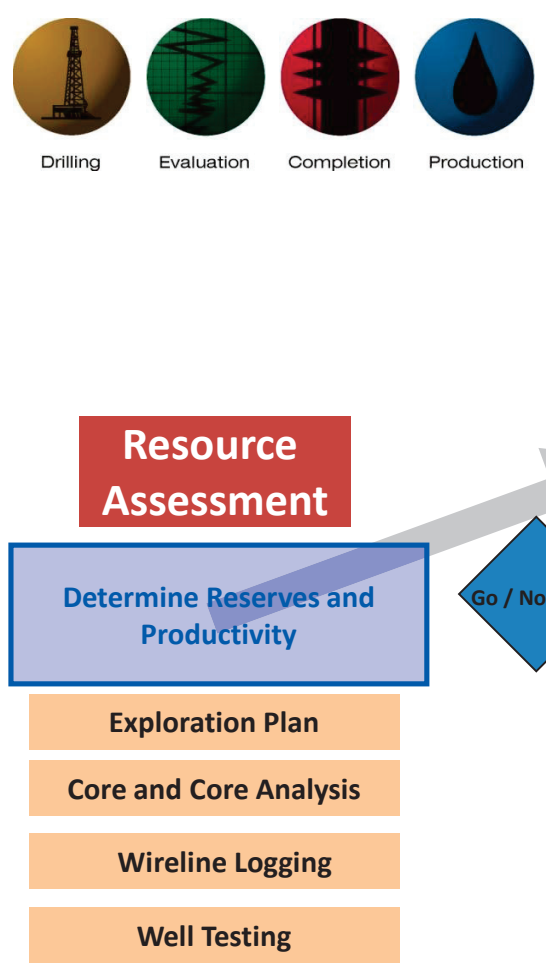

Reservoir Modeling

\section{Unconventional cas-OIl Field Development: Execution}

\section{Key Stages in "Typical” Shale Gas Development}

- Early evaluation (0-2 years)

- "Exploration" wells, resource appraisal

- Deliverability potential tests

- Pilot evaluation projects (1-3 years)

- Test economic feasibility in multiple areas

- Begin completion optimization

- Commercial development (3-10 years)

- Manufacturing approach

- Intensive early efforts

- Pad drilling and completion

- Construction of facilities and gathering system

- Long term production (20-60 years)

- Much less surface activity over time

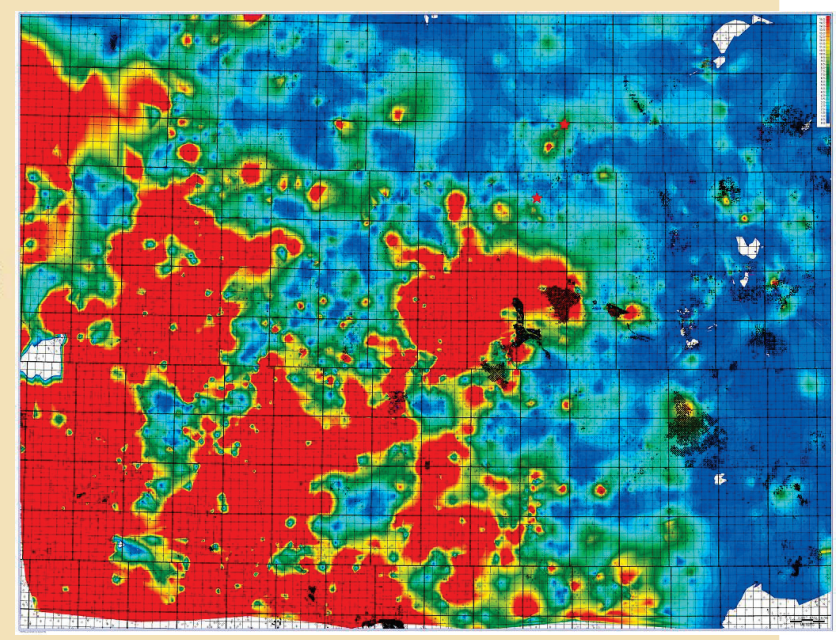

- Stakeholder Engagement

- Ongoing in all above stages 


\section{Added Value of Reservoir Evaluation vs. Well Costs}

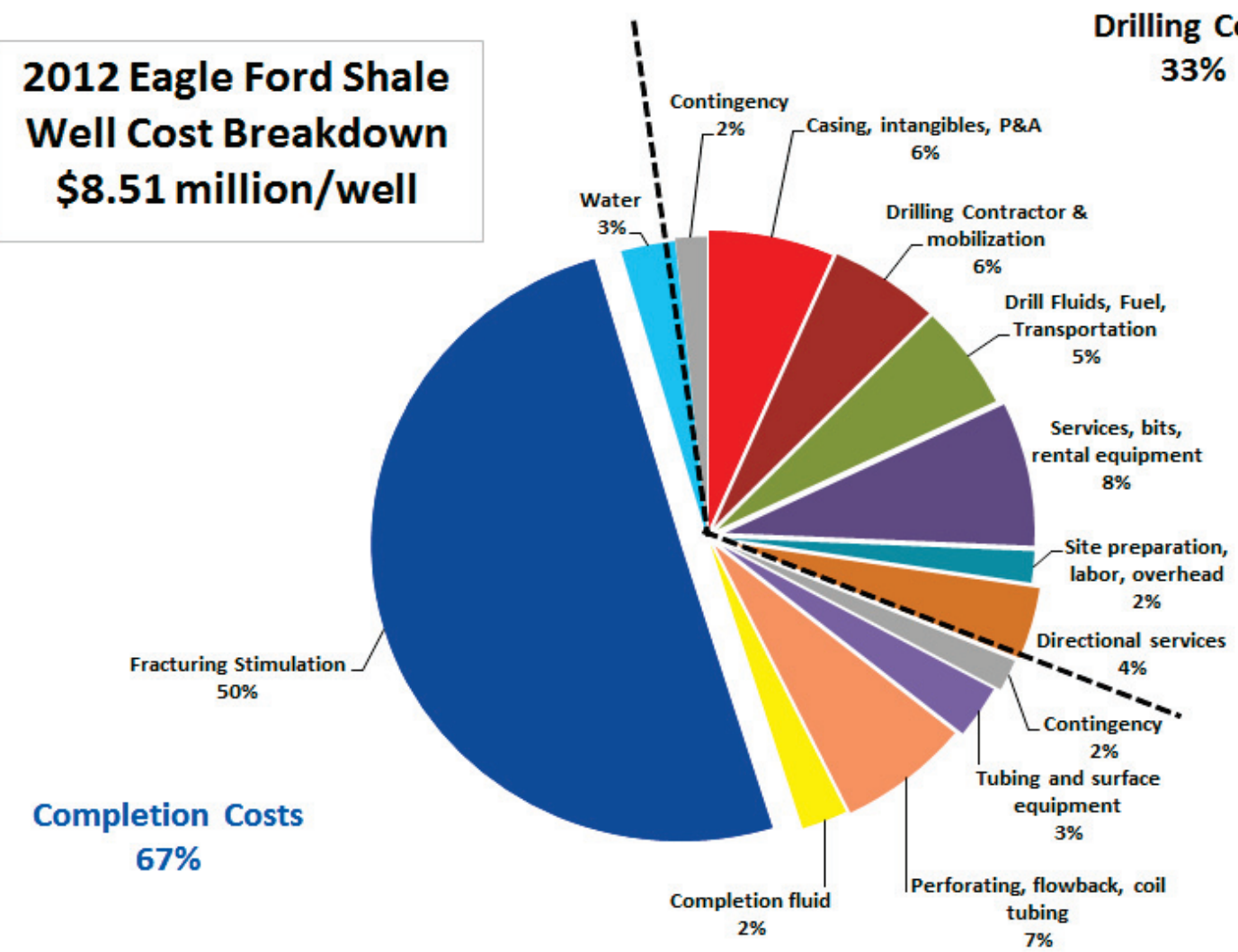

Added Value of Reservoir Evaluations vs. Well Costs

- Estimated costs to acquire and comprehensively evaluate geophysical logs, core, and fluids from a stratigraphic well - \$850K USD

- Estimated costs to properly perform prospect evaluation of an asset (assuming 10 Strat wells) \$8.5MM USD

- Cost to develop a single Section (assuming 6 lateral wells per Section) - \$60MM USD

- Costs to develop a reliable subsurface reservoir model (structured within a geological and stratigraphic framework) compared to field development of $\mathbf{2 5}$ square miles $-\mathbf{0 . 6 \%}$ 


\section{Unconventional Reservoir Prospect Appraisal Core Analysis Program}

- On-Site Gas Content and Gas Composition

- LECO $^{\text {TM. }}$ Total Organic Carbon

- Programmed Pyrolysis

- Vitrinite Reflectance and Visual Kerogen Assessment

- Oil Fingerprinting

- Biomarkers

- Gas \& Oil Isotope Geochemistry

- SRP (Permeability, Porosity, Fluid Saturations)

- Adsorption Isotherms

- X-Ray Diffraction (Bulk and Clay)

- X-Ray Fluorescence

v (Chemostratigraphy)
- Rock Mechanical Properties and Associated Acoustic Velocity Measurements

- Fluid Sensitivity Studies

- PVT Studies

- Core Gamma Ray (Spectral Gamma Recommended)

- CT Scan - Coming Soon

- Core Slab Descriptions (Sedimentology and Sequence Stratigraphy)

- Digital Photographs

- Whole Core Natural Fracture Description

- Thin Section Description

- Scanning Electron Microscopy

\section{Primary Prospect Evaluation Goals}

- Characterize Bulk Rock Properties

- Determine Gas/Oil-in-Place Volumes

- Determine Permeability to Gas and Oil

- Define Rock Mechanical Properties and Regional Field Stresses

- Perform Core-to-log Calibration of Petrophysical Models

- Conduct Facies Classification and Ranking

- Predict SRV, Fracture Geometry, and Fracture Conductivity

- Input all Data for Accurate Reservoir Modeling

- Establish a Stratigraphic and Geological Framework to Facilitate the Prediction of Regional Reservoir Prospectivity
Core

Analysis

Reservoir Simulation

Reduce

Reservoir

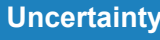

Well

Testing 


\section{Core Callbrated Log Interpretation}

$$
\begin{gathered}
G I P=1359.7 A h \rho G_{s t} \\
O I P=\frac{7,758.37 A h \phi S_{o}}{B_{o}}
\end{gathered}
$$

- Drainage Area $(A)$-can be arbitrarily set to 640 acres

- Reservoir thickness $(h)$, bulk density $(\rho)$, and total gas content $\left(G_{s t}\right)$ are all calculated from the log traces that were developed and at same resolution of the .LAS logs digits ( $0.5 \mathrm{ft}$ ).

- Resulting GIP estimates per depth "layer" are summed to provide accurate and high resolution estimates of GIP throughout the target formation Weatherford
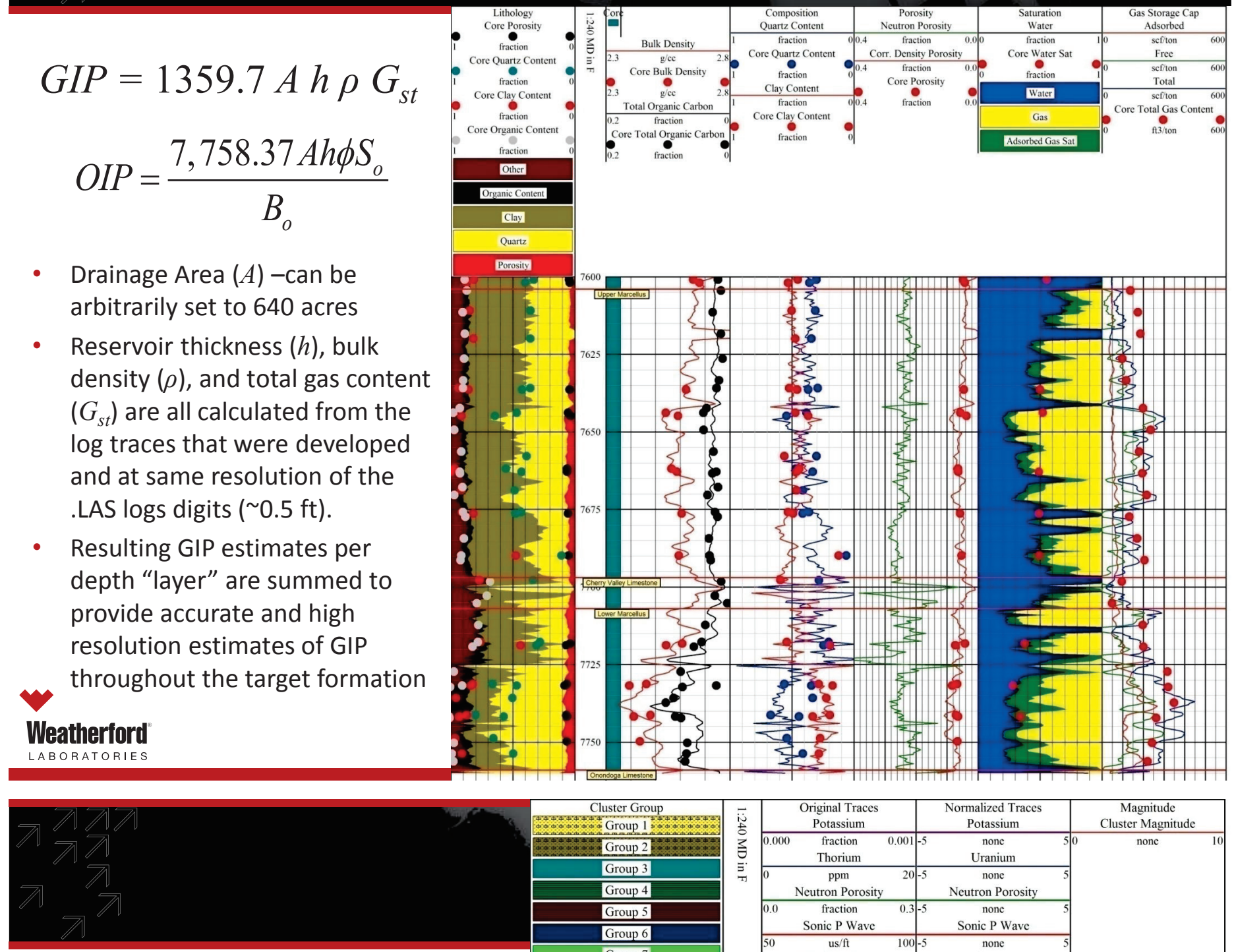

Cluster Analysis Provides Discrete "Lithofacies" Typing, which when coupled with core calibrated petrophysical models allows for facies classification and ranking.
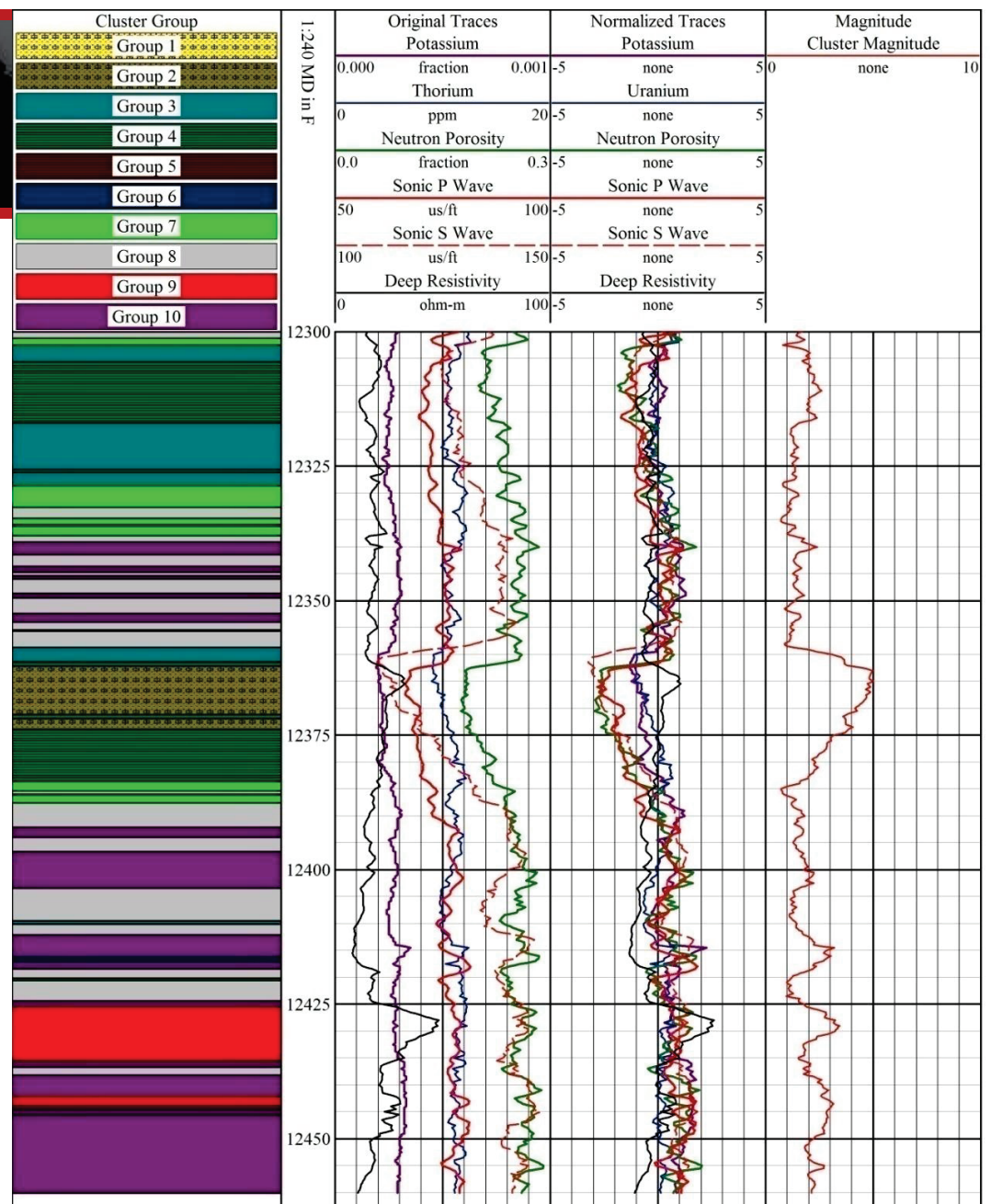


\section{Hydraulic Fracture Modeling}

Slickwater Treatment

-Total Clean Volume: 19,500 bbls.

-Total Proppant:

•Max. Proppant Conc.: 1.50 ppg

-Dimensionless Cond.: 32.85

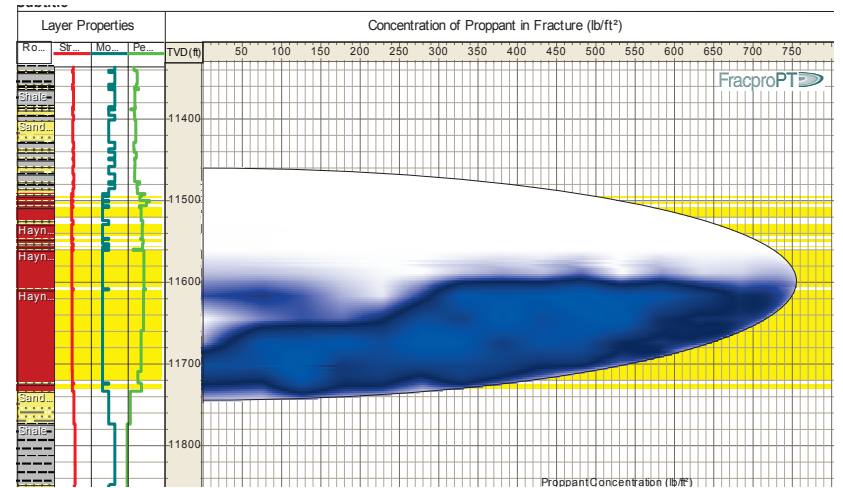

Hybrid Treatment

-Total Clean Volume: 7,440 bbls.

-Total Proppant: $\quad 360,000$ lbs.

-Max. Proppant Conc.: 3.5 ppg

-Dimensionless Cond.: 94.70

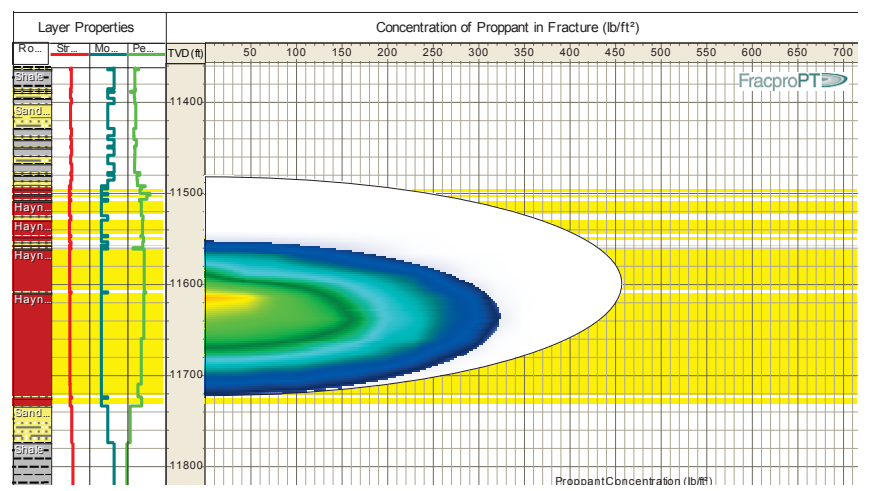

Weatherford

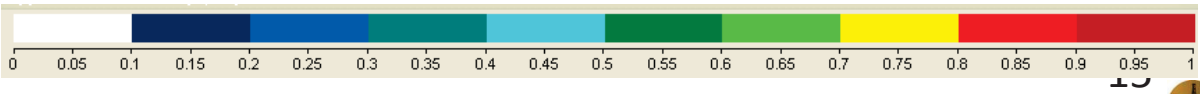

\section{Reservoir Modeling}

- CMG GEM Software

- Horizontal vs. Vertical

- Gas, Oil and Water Rates

- Peak Gas/Oil Rate

- Time to Peak Gas/Oil Rate

- Cumulative Production

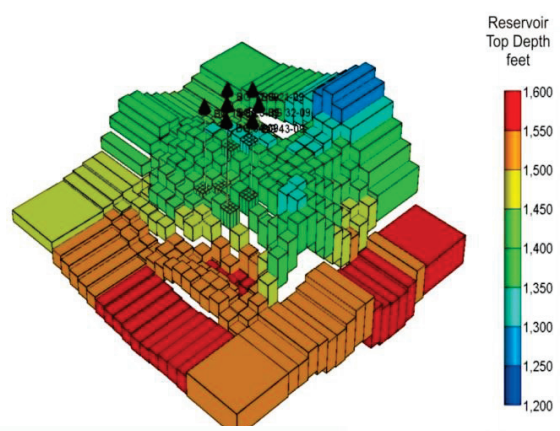

- Gas Composition over Production

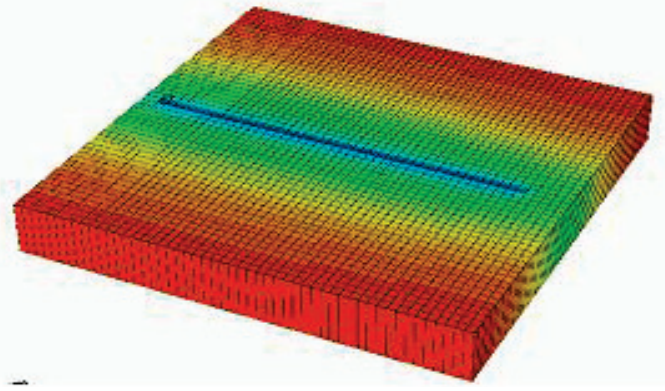




\section{Isopach Map Indicating High and Low Areas of Production Potential}

Criteria based on synergy between GIP and brittleness

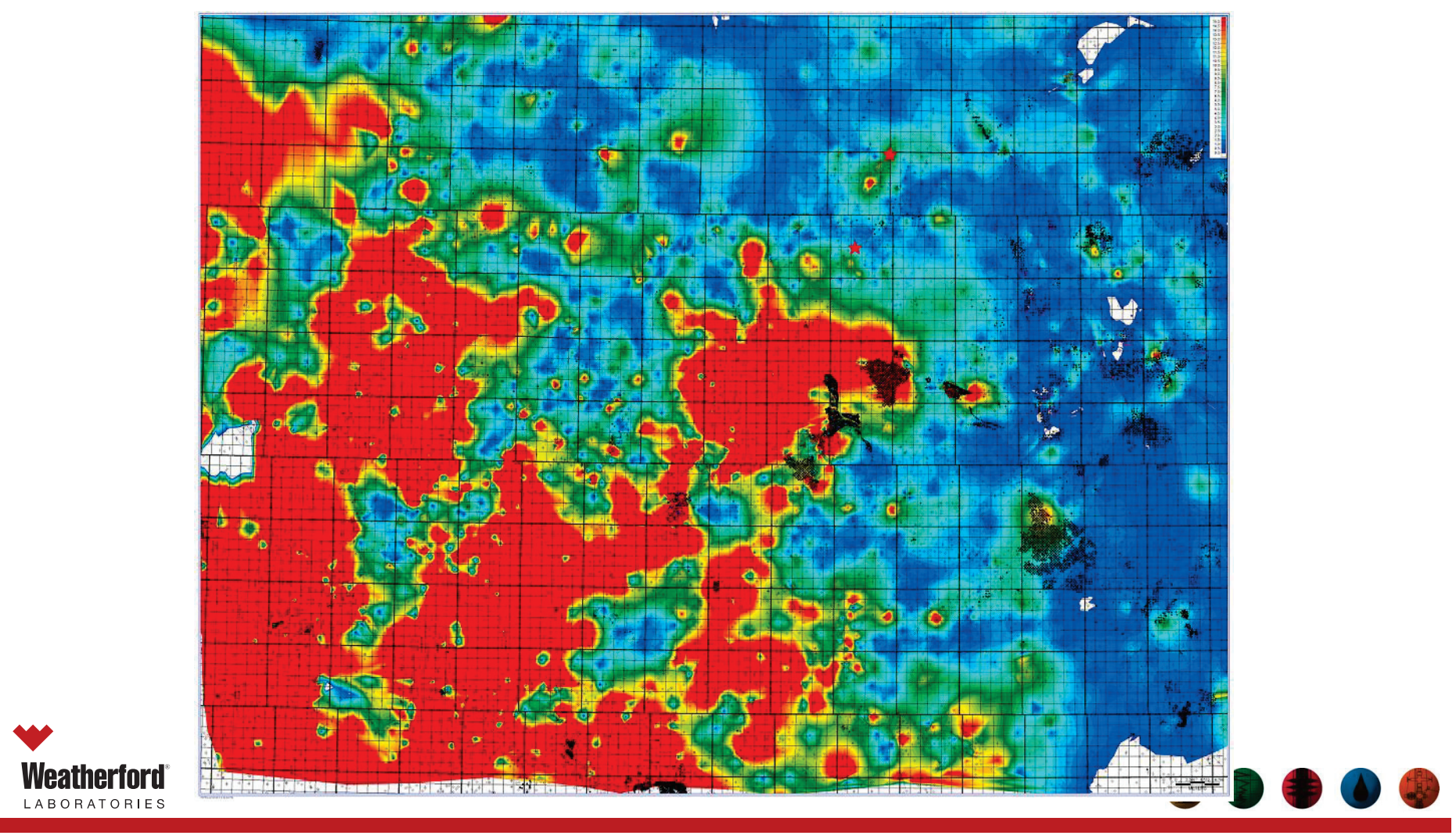

Added Value of Reservoir Evaluations vs. Well Costs

- Understanding of the sub-surface within a well defined geological and stratigraphic framework enables the drilling of intelligent, high productivity wells and predictions of well performance in different regions within the basin or field.

- Regional sweet spots

- Optimal vertical target zones

- What direction to drill the laterals (i.e. knowledge of field stresses)

- Optimized lateral geosteering (knowledge of formation geometry, avoidance of faults or unconformities)

- Optimal treatment and completions design

- Optimal bottom hole flowing pressure and artificial lift

v - Ability to maximize production and profit margins 


\section{Thank You}

For additional information, please contact:

Weatherford Laboratories

16161 Table Mountain Parkway

Golden, Colorado 80403

Dir: 720-898-8200

Cell: 303-519-9918
Chad Hartman

Chief Technical Advisor

chad.hartman@weatherfordlabs.com

Pat Jacobs

General Manager

pat.jacobs@weatherfordlabs.com 